\title{
Honorifics: A sociocultural verb agreement cue in Japanese sentence processing
}

\author{
YUKI YOSHIMURA \\ University of Massachusetts, Amherst \\ BRIAN MACWHINNEY \\ Carnegie Mellon University
}

Received: September 30, 2007 Accepted for publication: May 18, 2009

ADDRESS FOR CORRESPONDENCE

Yuki Yoshimura, Department of Languages, Literatures and Cultures, University of Massachusetts, Amherst, 161 Presidents Drive, Amherst, MA 01003. E-mail: yuki@ asianlan.umass.edu

\begin{abstract}
Case marking is the major cue to sentence interpretation in Japanese, whereas animacy and word order are much weaker. However, when subjects and their cases markers are omitted, Japanese honorific and humble verbs can provide information that compensates for the missing case role markers. This study examined the usage of honorific and humble verbs as cues to case role assignment by Japanese native speakers and second-language learners of Japanese. The results for native speakers replicated earlier findings regarding the predominant strength of case marking. However, when case marking was missing, native speakers relied more on honorific marking than word order. In these sentences, the processing that relied on the honorific cue was delayed by about $100 \mathrm{~ms}$ in comparison to processing that relied on the case-marking cue. Learners made extensive use of the honorific agreement cue, but their use of the cue was much less accurate than that of native speakers. In particular, they failed to systematically invoke the agreement cue when case marking was missing. Overall, the findings support the predictions of the model and extend its coverage to a new type of culturally determined cue.
\end{abstract}

Japanese uses specific affixes on the verb to mark social relations of power and solidarity (Brown \& Gilman, 1960; Brown \& Levinson, 1978). These markings, called honorifics, are a feature of Japanese that has often been used as evidence for the operation of links between language, culture and thought (Whorf, 1967). Apart from these links to Japanese culture, honorifics can also serve the more mundane function of helping to distinguish the actor of the transitive verb. This paper investigates the role of these honorific markings in sentence processing by native speakers, as well as second language (L2) learners. Our study is couched within the framework of the competition model (MacWhinney, 2008a; MacWhinney \&

(C) Cambridge University Press 2010 0142-7164/10 \$15.00 
Bates, 1989) that emphasizes the role of cue validity in shaping first language (L1) and L2 learning.

To interpret a transitive sentence, we have to decide who did what to whom. In doing this, a basic step is to identify the actor or agent. In the English sentence, the doctor examined the patient, native speakers interpret the doctor as the actor who is performing the action of examining someone. This is because nouns placed before active verbs are assigned the role of actor in English (MacWhinney, 2008b). In contrast, Japanese uses a completely different set of cues to determine the actor or agent. Although Japanese has a basic subject-object-verb (SOV) word order as in the doctor the patient examined, it also allows other word orders such as the doctor examined the patient (SVO), the patient the doctor examined (OSV), and the patient examined the doctor (OVS). In each of these sentences there is a possible interpretation with the doctor as the agent. However, instead of relying on word order cues, Japanese marks case by attaching certain particles directly after the noun. These case-marking particles include ga (subject marker), wa (topic marker), $o$ (object marker), and $n i$ (dative marker). Although Japanese linguists (Kuno, 1973) continue to debate the details of the functioning of this system, there is little disagreement regarding the general importance of case role markings in the language. The particle $g a$ is a particularly clear and reliable marker for the role of the actor or agent, and the particle $o$ is a clear marker for the object. For example, the sentence kanja (patient) $o$ (object marker) mita (examined) isha (doctor) $g a$ (subject marker) uses OVS order with the meaning that the doctor examined the patient, although this particular word order is not canonical in Japanese.

\section{THE COMPETITION MODEL}

The competition model holds that the "the forms of natural languages are created, governed, constrained, acquired, and used in the service of communicative functions" (MacWhinney, Bates, \& Kliegl, 1984). Specifically, the model holds that listeners use surface cues, such as word order and affixes, to assign case roles. However, the shape and strength of these cues vary markedly across languages.

Four core competition model concepts are: cue strength, cue validity, cue cost, and competition. The basic finding of the competition model research has been that cue strength is a direct function of cue validity, particularly in adult monolingual speakers. Cue strength is an information-processing construct that is computed using competition model experiments in which cues are placed into competition and strong cues dominate over weaker cues. Strength values are derived from analysis of variance (ANOVA) and maximum likelihood estimation analyses (McDonald \& MacWhinney, 1989). Conversely, cue validity is a text-based construct computed by examining cues in corpora of spoken and written language (McDonald \& Heilenman, 1991). Within the general framework of cue validity, we can further distinguish cue availability (i.e., whether the cue is present) and cue reliability (i.e., whether use of the cue leads to the correct interpretation). Studies with beginning learners have shown that cue availability is an important factor during the first stages of learning, 
but that reliability soon comes to take over as the major determinant of cue strength.

The tight relation between cue reliability and cue strength is further modified during learning by a set of factors covered under the general framework of "cue cost." Beginning learners find it easiest to pick up new forms that serve single functions and that have single surface realizations (Slobin, 1985). Although the case-marking particles of Japanese are high in reliability, they often express a variety of functions besides case marking. The additional cost of this semantic complexity tends to delay their acquisition by both L1 and L2 learners. Moreover, they can often be omitted, which tends to reduce their cue availability.

Previous studies in the framework of the competition model have shown that word order is the dominant cue for English (MacWhinney et al., 1984). In contrast, case marking is the dominant cue for adults in Japanese, Hungarian, and German. For various Romance languages, such as Italian, French, and Spanish, the dominant cue is subject-verb agreement. In Chinese, word order plays a large role, but the animacy contrast is an equally important determiner of sentence interpretation (Kail, 1989; Li, Bates, \& MacWhinney, 1993; MacWhinney et al., 1984; MacWhinney, Pléh, \& Bates, 1985; Pléh, 1989; Weyerts, Penke, Münte, Heinze, \& Clahsen, 2002). English is typologically unique in the extent to which it relies on word order to the exclusion of other cues.

\section{CUES IN JAPANESE L1 AND L2}

Competition model studies of Japanese (Sasaki \& MacWhinney, 2005) have shown consistently that case marking is the major cue to sentence interpretation. When the case-marking cue is absent, native speakers fall back on the animacy cue, not on word order (Kilborn \& Ito, 1989). Only when case marking and animacy contrasts are missing do listeners pay attention to word order cues. In that case, interpretation is governed by a first noun strategy, much as in German (MacWhinney et al., 1984) or Hungarian (Pléh, 1989). Using this strategy noun-verb-noun (NVN) is interpreted as SVO, NNV is interpreted as SOV, and VNN is interpreted as VSO.

Learners of Japanese, particularly those with L1 English, show a marked tendency to rigidify use of the SOV pattern in both production and comprehension. This effect may stem from the predominance of SOV input in textbooks at the elementary level. If learners find that they can uniformly rely on SOV order, they will engage in what Matessa and Anderson (2000) call "cue focusing," thereby failing to understand that word order is variable in Japanese and that, when case and word order conflict, case should dominate over word order. Learners also show a heavy reliance from the beginning on use of the animacy contrast. Gass (1987) has noted a universal tendency in beginning L2 learners to fall back on use of the animacy cue. In the case of Japanese, this reliance can remain in place during learning, because native speakers rely more on animacy than on word order. 


\section{CULTURAL DETERMINATION OF JAPANESE GRAMMAR}

Apart from these basic grammatical cues, Japanese sentence interpretation is shaped by four additional, culturally grounded, linguistic patterns: noun phrase (NP) ellipsis, topicalization, territory agreement, and honorific marking. Together, these four dimensions constitute a unique system for the cultural determination of Japanese grammar. Ellipsis plays an important role in Japanese conversations, because it allows speakers to maximize their reliance on common ground and shared knowledge (Clark, 1996). However, an important consequence of NP ellipsis is that information regarding case role marking is dropped along with the NP. Japanese sentences without subjects and objects are grammatical and natural (Kanaya, 2002; Kuno, 1973; Mikami, 1960). The following short dialogue illustrates the pattern.

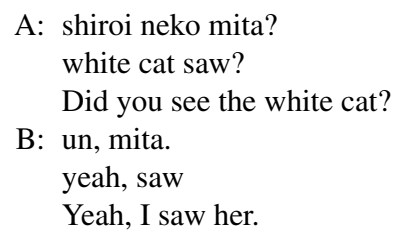

The subject is absent in utterance A, and both the subject and object are absent in utterance B. Yet, both sentences are perfectly grammatical (for more examples, see Kanaya, 2002). Kanaya (2002) attributes these patterns to the "stative" nature of Japanese culture, but English-speaking culture is "agentive." Japanese speakers prefer expressions that describe activities, whereas English speakers are more committed to specifying a named entity as an agential perspective. These contrasting cultural commitments are reflected in contrasting grammatical features.

Japanese also places heavy reliance on linguistic expression of the conversational feature of topicalization. In English, the marking of topic-comment structure is a secondary pattern, expressed occasionally through constructions such as the passive or the cleft (Halliday, 1966). However, in Japanese, speakers must continually choose between the subject particle "wa" that marks topicalization and the subject particle "ga" that expresses unmarked agency. The emphasis that Japanese places on this contrast reflects the importance of discourse cohesion in Japanese conversation. At the same time, learning of the contrast between "wa" and "ga" is a major challenge to L2 learners of Japanese who are less oriented toward the marking of topics.

Japanese grammar also relies on two culturally driven methods for marking agreement with the subject. The first of these two systems is what we will call "territory agreement." Kamio $(1994,1995)$ has shown that Japanese culture inhibits stepping into others' psychological or physiological territory. As a result, verbs and adjectives that describe a third person's mental state must be placed into a special conjugation. Adjectives are usually used with - garu for third person, and verbs that agree with third person subjects are used in the -teiru form. For example, adjectives like hoshii (want, desirable), ureshii (happy), itai (painful/hurt) are all 
used with the adjectival third person marker -garu as in hoshi-garu, ureshi-garu, ita-garu. Verbs like omou (think), and komaru (have trouble) are used in the -teiru form in omo-tteiru, and koma-tteiru. It is ungrammatical to say kanja (patient) ga (subject marker) itai (painful/hurt-first person, dictionary form), because the first person adjective cannot describe a third person's emotional state. Here, itai should be ita-garu (third person). This marking has a further important consequence for sentence processing. When these markers are used, even if the subject is dropped, there may be enough information to identify the agent as some third person identifiable from further context.

A second form of culturally driven agreement marking involves the use of honorific and humble verb affixes. These affixes can be attached to both transitive and intransitive verbs in Japanese. Honorific verbs cannot be used for the first person, but only for the second or the third person. It is particularly important to use these verbs when addressing superiors. Humble verbs can be used only for the first person or the speaker's in-group members. For example, the verb o-yomininari-mashita (polite-read-honorific-past) indicates that the agent is someone superior to the speaker. In this form there is both an polite prefix $o$ and the addition of ninari after the main verb and before the past tense marker. The form ninari derives from $n i+n a r u$ and translates literally as "become." However, in honorific verb forms, it functions to describe the actions of the agent in a less direct and therefore more honorific way. This subject-honoring form cannot be used when the subject is either the speaker or someone inferior to the speaker, unless the intention is to insult someone. Similarly, the form o-yomi-itashi-mashita (politeread-humble-past) indicates the humble way of expressing the action of a speaker or the speaker's in-group members. Note that the prefix $o$-is present in both the humble and subject-honoring form, and the actual distinction between the two is in the additional aspectual marker after the main verb stem. For our current purposes, the important fact is that, even without overt mention of their subjects, these honorific and humble verbs provide cues that may allow listeners to identify the agent.

Compared to territory agreement, the choice of humble or honorific marking is much more frequent. In the competition model terms, this means that honorific agreement has higher availability than territory agreement. Because subjects are frequently omitted in Japanese, there are many sentences where honorific agreement functions as the remaining reliable cue to sentence interpretation (Shibatani, 1985). Previous studies (Sasaki \& MacWhinney, 2005) have shown that the casemarking cue is the dominant cue in Japanese, when it is present. However, when this dominant cue is missing, honorific agreement marking can sometimes step in to fill the gap. There has not yet been any investigation of the role of honorific agreement in Japanese sentence interpretation. The present study is designed to fill this gap.

The second goal of the study is to examine how L2 learners use the honorific agreement cue. Unlike native speakers, L2 learners receive intensive explicit instruction in the use of this cue. This explicit instruction includes both cue focusing and a marked increase in exposure to relevant patterns, thereby increasing cue availability. Because of the heavy social weight associated with the correct selection of either humble or honorific verbs in production, learners 
come to view the learning of this system as an important part of learning Japanese. Together, these two factors might lead us to expect that L2 learners would come to rely heavily on this cue, despite its general low availability in the language.

\section{METHOD}

\section{Participants}

Twenty native Japanese speakers (16 advanced level learners who learn Japanese as a foreign language, and 29 intermediate level Japanese learners) participated in the study. Native Japanese speakers were recruited from various locations in Pittsburgh, Pennsylvania. They had a mean age of 31.6 and a mean length of residence in the United States of 3 years. L2 learners were students in advanced and intermediate levels of Japanese courses at Carnegie Mellon University. The L1s of the learners were English (60\%), Chinese (18\%), Korean (14\%), and other $(8 \%)$.

Intermediate learners meet in classes 4 days each week for $50 \mathrm{~min}$, and advanced learners meet 3 days each week. The teaching method relies on both oral and written texts and includes a few minutes of listening practice each day. Both intermediate and advanced learners have learned the honorific and humble verb systems in class. However, advanced learners have been exposed to these forms for a year longer than intermediate learners. Intermediate learners began their learning of honorific and humble verbs less than a month before they participated in the experiment. They continued using them both in class activities and written homework. Some of advanced learners had studied in Japan, although none of them had been in Japan for more than 3 months.

\section{Stimuli}

Sentences were composed of two nouns and a transitive verb. The sentence structures were varied to control the effects of the three factors of Word Order, Case, and Agreement, with three levels for each factor. The Word Order factor had the levels of NNV, NVN, and VNN orders. The three levels for the Case factor were Nom_Dat, Dat_Nom, and Zero. In the Nom_Dat condition, the first noun was given nominative marking and the second noun was given dative marking. In the Dat_Nom condition, the second noun was given nominative marking and the first noun was given dative marking. In the zero marking condition, neither noun was marked. For example, Sentence 1 describes a condition where an honorific verb agrees with a nominative case that marks the noun that carries honorability between the two nouns. Sentence 2 describes the condition when the case-marking cue competes with the agreement cue. Sentence 3 has no cue competition and no case-marking cues available.

1. Teacher NOM Student DAT HonorificVerb.

2. Teacher DAT Student NOM HonorificVerb.

3. Teacher Student Honorific Verb. 
The three levels for the Agreement factor were agree, disagree, and neutral. In the agree condition, the verb agreed with either the honorific or humble status of the first noun (e.g., Sentences 4 and 5). In the disagree condition, the verb did not agree with the honorific or humble condition of the first noun. Instead, it agreed with the honorific status of the second noun (e.g., Sentences 6 and 7). In the neutral condition, the verb was a plain form that carried no agreement cue. The verbs used in the experiment were limited to high-frequency verbs such as talk, meet, and ask, that were familiar to both intermediate and advanced levels of learners. Half of the agreement conditions used honorific verbs and the other half used humble verbs along with noun features differing in positional superiority.

4. Teacher Student HonorificVerb.

5. Student Teacher HumbleVerb.

6. Teacher Student HumbleVerb.

7. Student Teacher HonorificVerb.

Table 1 illustrates the complete design for NNV sentences only. In that table the honorable noun is teacher, the humble noun is student, the honorable verb is o-hanishi-ninari-masu, the humble verb is o-hanishi-itashi-masu, and the neutral verb is hanashi-masu. Parallel tables for NVN and VNN orders would provide a complete representation of the full design.

To control animacy effects, all nouns were selected to be animate. Each condition consisted of a noun combination differing in occupational superiority such as teacher-student, general-soldier, and president-employee. Humble verbs are often used for an action of a speaker him-/herself, but because of a variety of participants' occupation, the stimuli created a situation that involves two persons with a clear difference in the degree of honorableness, where participants perceive a noun with low honorableness in each sentence stimuli is supposed to be driven by a humble verb to the other noun. The function is categorized to an honorific usage for speakers' in-group members that include speakers' family, friends, and colleagues depending on a situation (Shibatani, 1990). Each picture was labeled with the referent's occupation to make it clear which picture corresponded to which occupation.

In addition to sentences constructed using these three factors, filler sentences were inserted to breaking up any tendency to lock into specific modes of processing for specific verb types. The filler sentences used plain verbs, proper nouns without honorific markings, and animal names. The filler sentences also varied their use of NVN, VNN, and NNV word orders.

All three factors were fully crossed with three levels for three participant groups: native Japanese speakers, advanced L2 learners, and intermediate L2 learners. The full-factorial design of $3 \times 3 \times 3$ had 27 cells. Each cell included two replicates for a total of 54 test sentences in addition to 18 filler sentences. The following examples illustrate the three possible sentence types for NNV order with Nom_Dat case marking. Example 8 shows agreement with the first noun, Example 9 shows agreement with the second noun, and Example 10 uses a neutral verb with no honorific agreement marking. 
Table 1. Example schematic stimuli for $3 \times 3$ crossing of case and agreement for noun-noun-verb word order

\begin{tabular}{|c|c|c|c|c|}
\hline \multirow{3}{*}{$\begin{array}{c}\text { Honorific } \\
\text { Agreement } \\
\text { With N1 } \\
\text { Neutral }\end{array}$} & \multicolumn{4}{|c|}{ Case Marking } \\
\hline & \multicolumn{2}{|c|}{ No Case } & \multicolumn{2}{|c|}{ Nom-Dat } \\
\hline & Teacher student & Hanashi-masu & Teacher NOM student DAT & Hanashi-masu \\
\hline & Student teacher & Hanashi-masu & Student NOM teacher DAT & Hanashi-masu \\
\hline \multirow[t]{2}{*}{ Agree } & Teacher student & O-hanashi-ni-nari-masu & Teacher NOM student DAT & O-hanashi-ni-nari-masu \\
\hline & Student teacher & O-hanashi-itashi-masu & Student NOM teacher DAT & O-hanashi-itashi-masu \\
\hline \multirow[t]{2}{*}{ Disagree } & Teacher student & O-hanashi-ni-nari-masu & Teacher NOM student DAT & O-hanashi-ni-nari-masu \\
\hline & Student teacher & O-hanashi-itashi-masu & Student NOM teacher DAT & O-hanashi-itashi-masu \\
\hline \multicolumn{5}{|c|}{ Dat-Nom } \\
\hline \multirow[t]{2}{*}{ Neutral } & Teacher_DAT student NOM & Hanashi-masu & & \\
\hline & Student DAT teacher NOM & Hanashi-masu & & \\
\hline \multirow[t]{2}{*}{ Agree } & Teacher_DAT student NOM & O-hanashi-ni-nari-masu & & \\
\hline & Student DAT teacher NOM & O-hanashi-ni-itashi-masu & & \\
\hline \multirow[t]{2}{*}{ Disagree } & Teacher_DAT student NOM & O-hanashi-ni-nari-masu & & \\
\hline & Student DAT teacher NOM & O-hanashi-ni-itashi-masu & & \\
\hline
\end{tabular}


Yoshimura \& MacWhinney: Honorifics in Japanese
8. sensei ga gakusei ni o- hanashi- ninari- masu. teacher SUB student DAT polite talk-V-stem honor V-end "The teacher honorably talked to the student."
9. sensei ga gakusei ni o- hanashi- itashi- masu. teacher SUB student DAT polite talk-V-stem humb V-end "The teacher humbly talked to the student."
10. sensei ga gakusei ni hanashi- masu. teacher SUB student DAT talk-V-stem V-end "The teacher talked to the student."

Sentences were composed by random selection from the relevant word pools. These included six nouns (three superior and three subordinate nouns), three case-marking forms (nominative, dative, and zero), five base verbs each in three agreement forms (honorific, humble, and plain), and five unmarked nouns (no superiority difference). A male native Japanese speaker recorded the words with a normal reading speed with no geographical accents. The audio files were digitized with 16-bit monaural .wav format at a $22-\mathrm{kHz}$ sampling rate. Each sound file of nouns and verbs was combined into the appropriate sentence pattern by random selection from the word types.

\section{Procedure}

Participants listened to sentences composed of two nouns and a simple verb over a headphone. As the audio for the sentence began, the computer screen displayed two pictures describing the nouns in the sentence. The pictures remained displayed until participants pressed a key indicating their choice of one of the pictures as the agent. Directly above the pictures were the Kanji characters for the nouns, along with the corresponding Furigata form (a phonetic form in Hiragana). For example, "teacher" (in Kanji and Furigata) was shown on top of the picture "teacher." This was done to help the L2 learners remember which picture corresponds to which noun.

All instructions were given in English through screens on the computer. Participants were asked to choose the picture that they thought performed the action of the verb described in each sentence. They were instructed to choose either of the two nouns as agent, and to push a button corresponding to either of two pictures shown on the computer screen. If they thought the person on the right side did an action, they pressed the right button. If they thought the person on the left side did an action, they pressed the left button. They were instructed to press the button as quickly as possible after they heard a sentence. Participants were given five practice sentences before the first test sentence began.

All participants were tested individually in an experiment lab and they were asked to complete the same task. To refresh their memory and make them comfortable about the use of honorific and humble verbs, each nonnative participant went through a brief one-screen review of the relevant verb conjugations. This review involved presenting the relevant verbs on the computer screen in Japanese. Nonnative participants also went through a review of nouns such as general versus soldier and president versus employee, which were used in the experiment. They 
were instructed not to worry about remembering these nouns because labels appear above noun pictures, and also that the experiment was not designed to test their language proficiency in any sense. Participants were told that sometimes sentences were culturally inappropriate or grammatically incorrect. They were asked to respond as quickly as possible, even if they found some sentences unnatural. The whole experiment lasted between 15 and $20 \mathrm{~min}$.

\section{RESULTS}

\section{First noun choice}

There were two dependent variables: first noun choice and response time (RT). The first set of analyses looks at the dependent variable of first noun choice. The overall analysis was a mixed factorial analysis with three within-participants factors (Case, Agreement, and Word Order) and one between-participants factor (Native, L2 advanced, L2 intermediate). The overall full-factorial analysis showed no significant interactions: Case $\times$ Agreement $\times$ Order: $F(8,496)=.172, p=$ .994 , Case $\times$ Agreement $\times$ Order $\times$ Participants Group: $F(16,496)=.912, p=$ .555. For further analysis, only significant effects will be reported. There were highly significant main effects of Case, $F(2,124)=167.567, p<.001$, and Agreement, $F(2,124)=32.915, p<.001$. All three groups relied heavily on both of these cues for sentence interpretation. However, the Word Order factor was not significant, and there were no significant interactions involving the word order cue. This indicates that none of the three groups used the word order cue for subject identification in any condition. There was also no significant main effect for the between-participant factor.

The interaction between case and agreement was highly significant, $F(4,248)=$ $16.431, p<.001)$ Figure 1 shows the shape of the competition between these two cues. When the first noun was in the nominative case and the second NP was in the dative case (Nom_Dat), the percentage of first noun choice for agent identification was high, regardless of the level of agreement. Similarly, when the first NP was in the dative and the second NP was in the nominative (Dat_Nom), first noun choice was low, regardless of the level of agreement. In contrast, when case was absent, the agreement cue had a large effect on first noun choice. As shown in Figure 1, the bar in the zero case condition stretched out from $34 \%$ for the disagreeing to $73 \%$ for the agreeing condition.

There was also a highly significant interaction of group and case, $F(4,124)=$ $25.130, p<.001$. Figure 2 illustrates native speakers' strong reliance on case compared to the L2 learners. Native speakers' showed a $96 \%$ level of first noun choice in the Nom_Dat condition and 7\% in the Dat_Nom condition. This indicates that native speakers ignore the honorific agreement cue when case is available. Advanced learners were more similar to native speakers than were intermediate learners. However, both learner groups relied less strongly on the case cue than did native speakers.

Although native speakers and L2 learners did not differ in their use of the agreement cue by itself (see Figure 3), the three-way interaction of 
Agreement $x$ Case

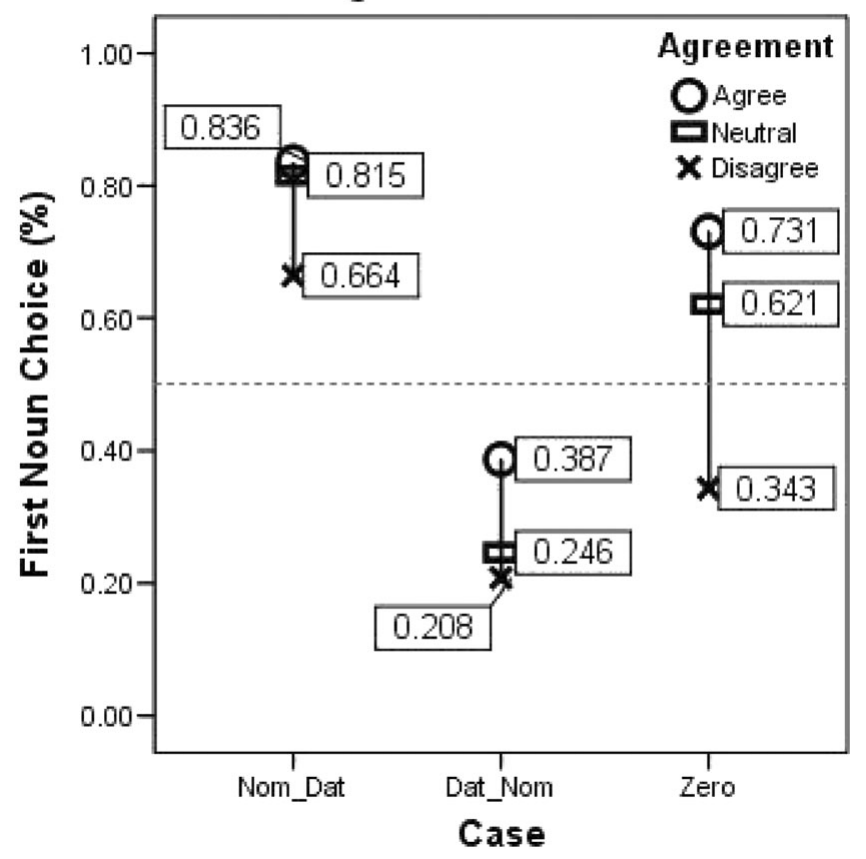

Figure 1. The interaction between agreement and case.

Case $\times$ Agreement $\times$ Group was highly significant, $F(8,248)=8.279, p<.001$. Additional detailed analyses showed that this effect was centered in the zero casemarking condition. Figure 4 shows that, when case marking is absent, native speakers relied on agreement more heavily than do learners. When a verb agreed honorifically with the first noun, first noun choice was $85 \%(S D=0.194)$. However, when a verb did not agree with the first noun, first noun choice decreased to $18 \%(S D=$ 0.186). When honorific agreement favors the first noun, then native speakers realize that this is the actor in the sentence. When honorific agreement favors the second noun, then native speakers will choose the second noun as the agent. Learners have not yet acquired this pattern.

\section{$R T$}

The first noun choice results indicate the honorific agreement cue plays a determinant role when the case-marking cue is not available. However, it is possible that this complex cue may be far more difficult to compute on line. Therefore, we also wish to understand whether native speakers use this cue in an automatic and intuitive way. In the three-way mixed-model ANOVA, there was a highly significant main effect of group, $F(2,62)=10.272, p<.001$. Pairwise comparisons showed 


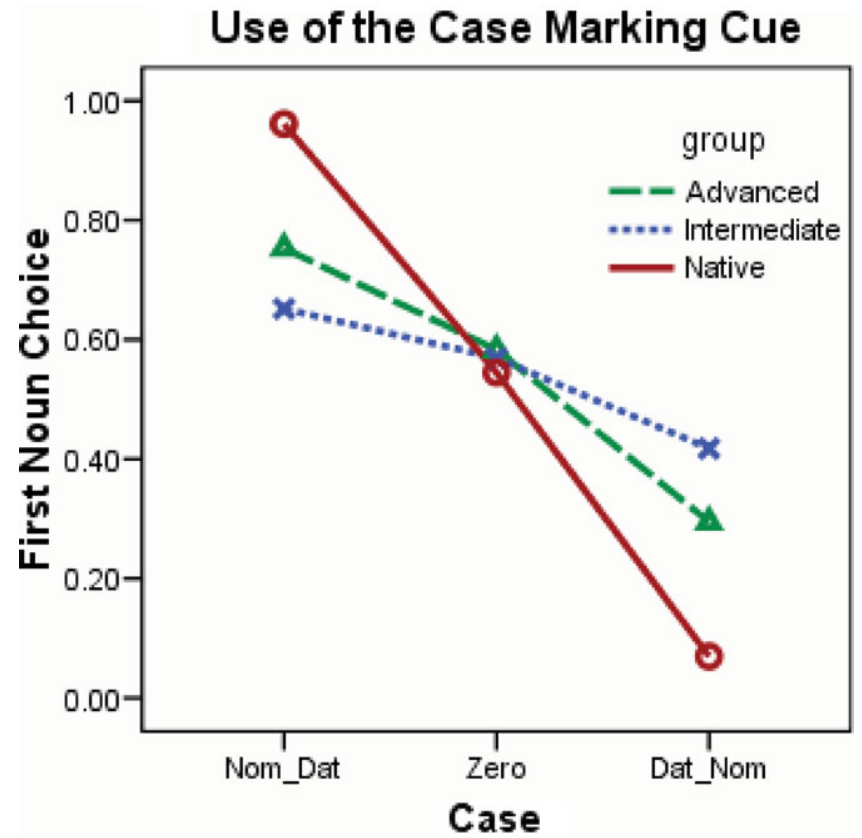

Figure 2. A group comparison for case on first noun choice. [A color version of this figure can be viewed online at journals.cambridge.org/aps]

that native speakers were much faster than L2 learners (native vs. advanced, mean difference $=-495 \mathrm{~ms}, S E=161.31, p<.01$; native vs. intermediate, mean difference $=-620 \mathrm{~ms}, S E=139.78, p<.001$ ), whereas there was no significant difference between the two groups of L2 learners. The differences in RTs between native speakers and L2 learners on each cue are illustrated in Figure 5. The three segments of Figure 5 show that native speakers are faster across the board on all cue configurations. In addition, these segments show that, although advanced learners are much slower than native speakers, their pattern across cues matches that of native speakers. However, intermediate learners do not reflect the native speaker pattern in the same way.

To further understand the impact of cue competition on RTs, we focus on the results for the native speakers, because these provide the best examples of intuitive, automated processing. A three-way ANOVA for the native speaker group produced significant main effects for case, $F(2,38)=9.567, p<.001$, agreement, $F(2$, $38)=5.455, p<.01$, and word order, $F(2,38)=4.247, p<.05$.

Within the native speaker group, we first look at the main effects for case and agreement. As shown in Figure 5a, native speaker cue choice was particularly fast when case was available, with more than a 250-ms speedup compared with the zero case condition: Nom_Dat $\times$ Zero_Case, $F(1,19)=11.327, p=.003$, Zero_Case $\times$ Dat_Nom, $F(1,19)=8.500, p=.009$. In contrast, as shown in Figure 5b, the RTs for native speakers were moderately slower when the 


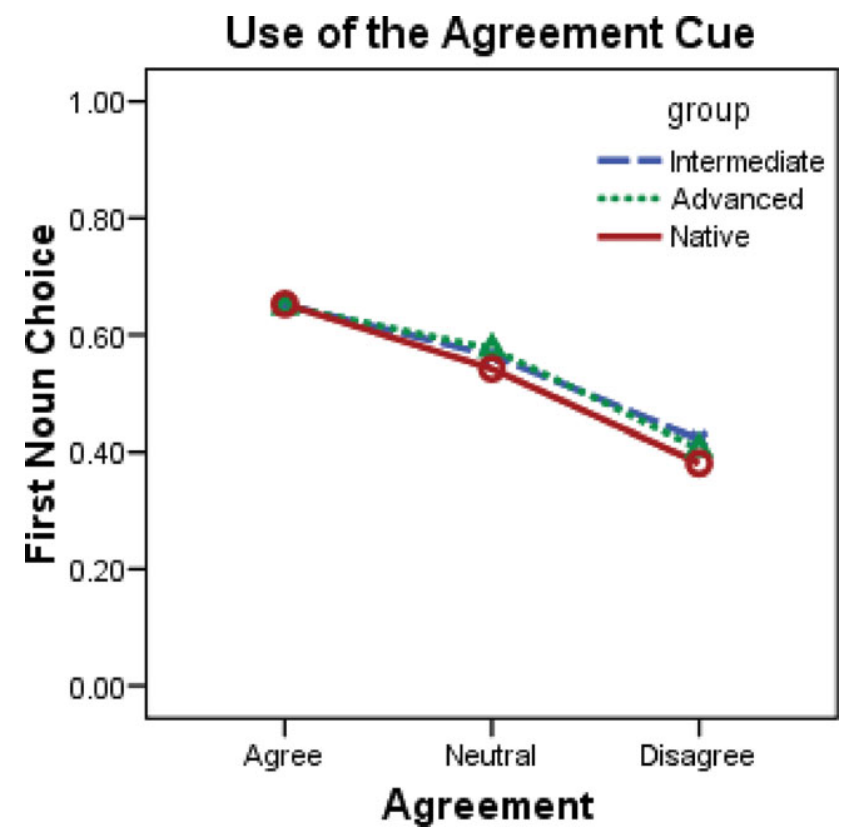

Figure 3. A group comparison for agreement on first noun choice. [A color version of this figure can be viewed online at journals.cambridge.org/aps]

agreement cue was available (agree and disagree), than when it was missing (neutral): Agree $\times$ Neutral, $F(1,19)=6.551, p=.019 ;$ Neutral $\times$ Disagree, $F(1$, 19) $=6.030, p=.024$; Bonferroni $p=0.17$.

These two main effects for case and agreement can be understood in terms of the processing needed for each cue type. Case marking is a highly reliable cue that is marked locally on each noun. Once a native speaker detects the presence of this cue, RTs can be very fast. By contrast, honorific agreement processing requires that the form of the verb be matched up with the social status of the agreeing noun. This nonlocal processing takes far more time than the processing for case, thereby producing a different pattern for RTs.

The analysis also revealed a significant interaction between case and agreement, $F(4,76)=3.655, p<.01$. Whenever the case-marking cue was available, case won over agreement. However, as Figure 6 shows, the RTs in the agreeing and disagreeing conditions were slower compared to the neutral condition in both Nom_Dat and Dat_Nom conditions. In addition to nonlocal processing loads on the agreement cue, the availability of multiple cues in a condition appears to be causing a nearly 200-ms delay. When case was absent, the RTs were all much slower regardless of the agreement status.

The main effect of word order, as reported earlier, can be analyzed with further details by native speakers' performance. The RT for NNV by native speakers was slower than that for NVN, and there was no significant difference between the RTs 


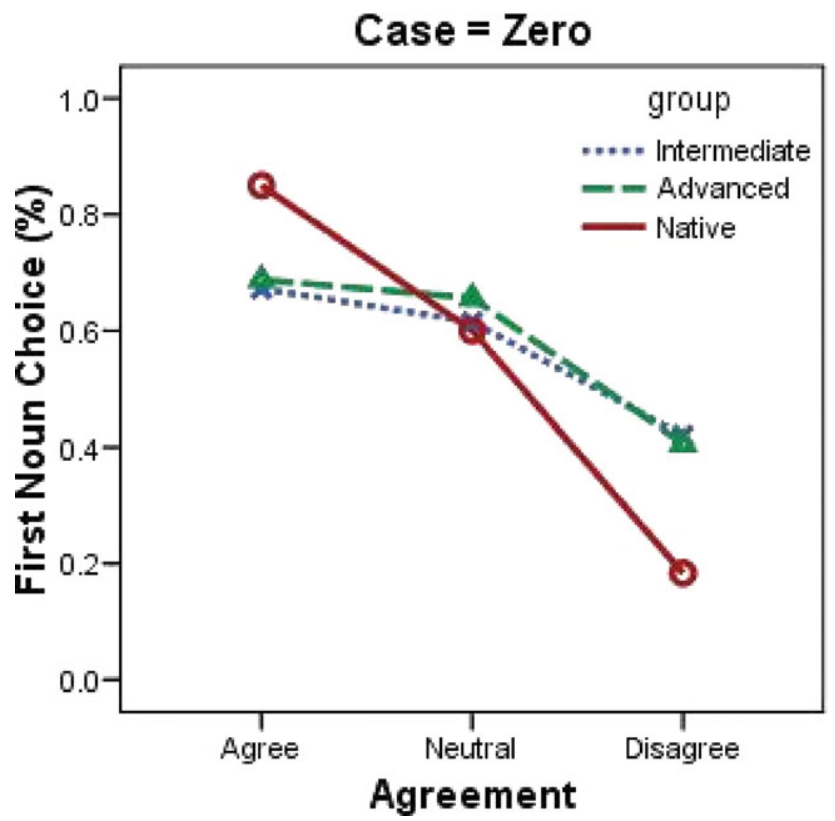

Figure 4. The agreement in case zero on first noun choice. [A color version of this figure can be viewed online at journals.cambridge.org/aps]

of NNV and VNN, as shown in Figure $5 \mathrm{c}$ : NVN $\times$ NNV, $F(1,19)=12.453, p=$ $.002 ; \mathrm{VNN} \times \mathrm{NNV}, F(1,19)=2.564, p=.126$; Bonferroni $p=0.17$. However, this main effect is qualified by the significant interaction of word order with case, $F(4,76)=2.783, p<.05$, displayed in Figure 7 . This effect arises from native speakers relying on the honorific agreement cue when case marking is missing. However, in NNV word order, this cue will not reveal itself until the verb appears at the very end of the sentence. This means that native speaker listeners have to wait until the very end to evaluate the information that might be provided by the agreement cue, thereby adding an additional slowdown in RTs.

Overall, this analysis of native speaker RT data showed that native speakers were faster than L2 learners in every condition. Native speakers' performance in the zero case condition shows that delays can occur, when expected cues are missing. However, when strong, reliable cues are available early in the sentence, decisions are relatively fast.

\section{DISCUSSION}

The results of the study contribute in several ways to the ongoing development of the competition model and psycholinguistics more generally. First, the results provide further support for the claim that the case-marking cue is the dominant cue in Japanese. Despite the presence of the honorific verb agreement cue, native 
Yoshimura \& MacWhinney: Honorifics in Japanese

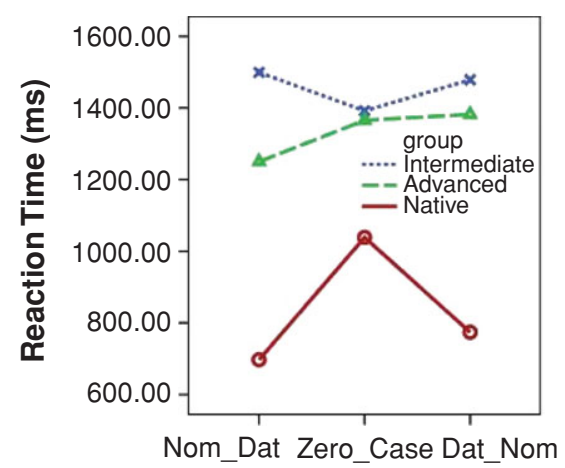

(a)

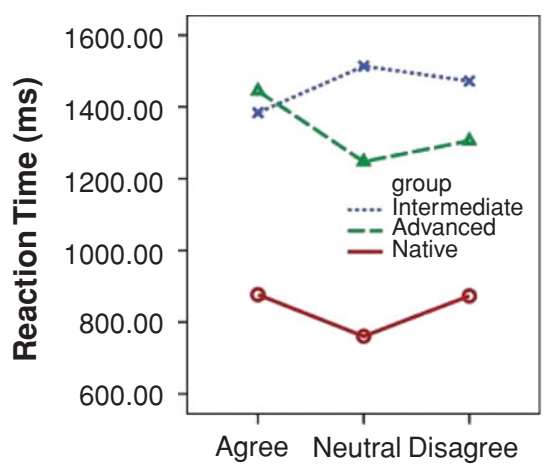

(b)

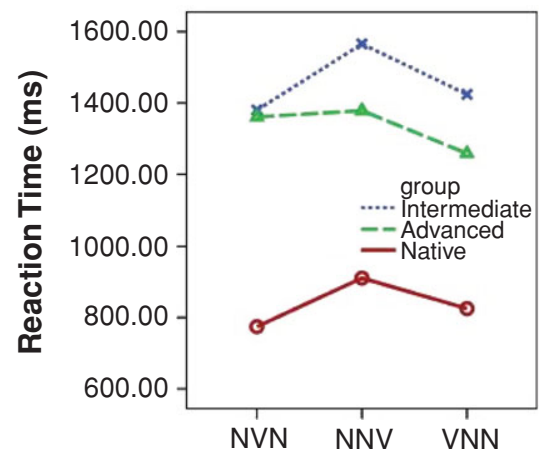

(c)

Figure 5. Reaction times for (a) case, (b) agreement, and (c) word order. [A color version of this figure can be viewed online at journals.cambridge.org/aps]

speakers consistently chose nouns marked by the nominative case for agent identification. Second, when case was absent, the honorific agreement cue played an important and reliable role, as a cue to help determining the agent. For native speakers, honorific agreement was a stronger cue than word order. This is an important finding, because it shows that a highly reliable, culturally determined cue can be more powerful than a less reliable grammatical cue, even when the latter is higher in availability. This result underscores the recurrent finding for native speakers that cue strength is a direct function of cue reliability.

In this regard, it is important to note that languages like Chinese ( $\mathrm{Su}, 2001)$, Hungarian (Pléh, 1989), and German (MacWhinney et al., 1984) rely heavily on animacy, although that cue is not tightly linked to grammar or syntax in those languages. This indicates that we have to take a view of sentence interpretation cues that includes a wide variety of possible social, syntactic, and semantic functions.

Third, although native speakers rely heavily on the honorific agreement cue when case is not available, their processing of this cue is slower than for the 
Case x Agreement

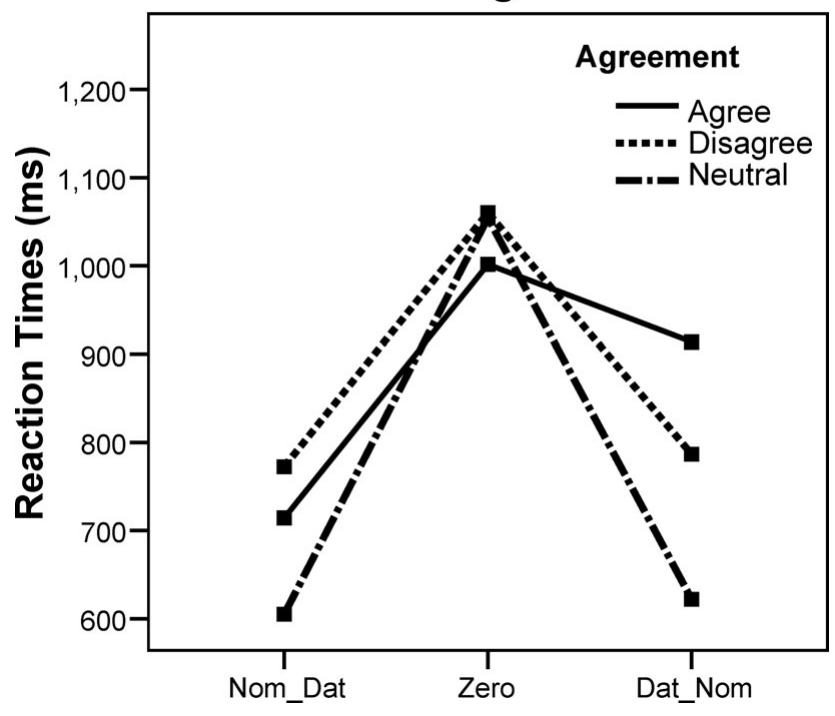

Figure 6. Reaction times for case and agreement.

\section{Case x Word Order}

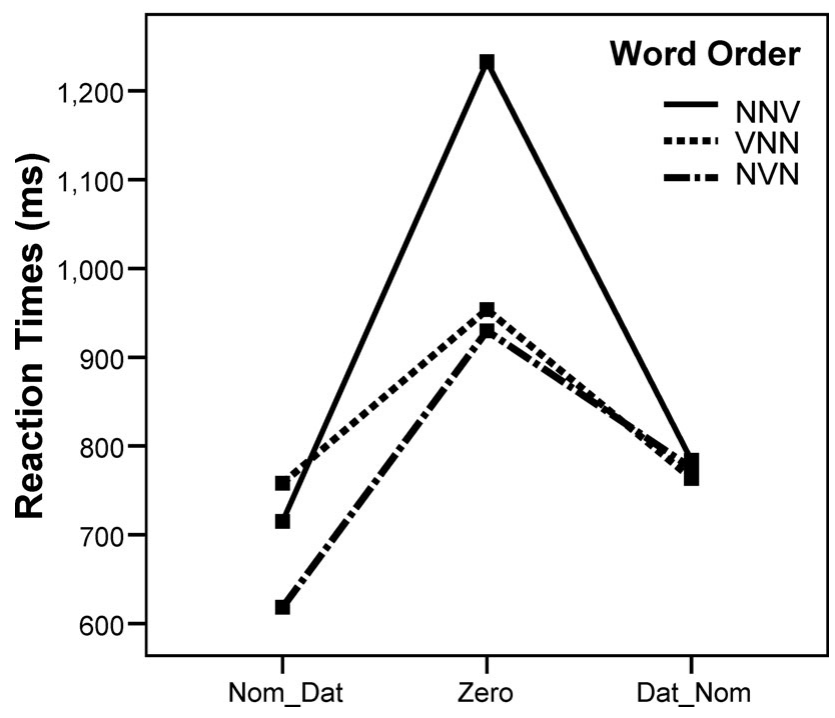

Figure 7. Reaction times for case and word order. 
case cue. The competition model characterization of this RT delay focuses on the notion of processibility. In RT work with German and Russian learners (Kempe \& MacWhinney, 1998), German and Russian monolinguals (Kempe \& MacWhinney, 1999), Italian children (Devescovi, D’Amico, Smith, Mimica, \& Bates, 1998), and English (Pearlmutter, Garnsey, \& Bock, 1999), researchers have shown that the processing of subject-verb agreement places heavy demands during online processing. The model attributes these effects to the local cue nature of case (Slobin, 1985) versus the nonlocal cue nature of honorific agreement, which requires matching of the verb to alternative nouns elsewhere in the sentence. However, the slower RTs for the agreement cue could also be related to the honorific agreement being much less frequently available, compared to the case cue. Additional work will be needed to distinguish these two possibilities.

Apart from these three major findings for native speakers, the study also provided important information regarding cue acquisition by L2 learners. As predicted, their usage of both the case-marking cue and the honorific agreement cue was more variable than that of native speakers. It is interesting that they overused the honorific agreement cue even when the case-marking cue was available to use. In part, this overuse could have been triggered by the experimental session beginning with a one-screen review of the relevant aspect of the conjugational paradigm, thereby emphasizing the role of honorific agreement. However, in comparison to native speakers, learners did not use the honorific cue as much as they could. This suggests that learners' use of the case-marking cue has not yet stabilized at the level of native speakers after about 3 years of learning Japanese, despite the initial review of the paradigm. Moreover, the overuse of the honorific cue indicates that learners tend to focus on a single cue when it is at the focus of an instructional module or experiment. The tendency to focus on individual cues may prevent them from acquiring the relative strength of each cue among all available cues in the target $\mathrm{L} 2$. To counteract this tendency, instructors may need to present learners with input that illustrates competition between the relevant cues. By presenting cues in direct competition, instructors can help learners establish the correct dominance relations between the cues (McDonald \& MacWhinney, 1991).

Input quantity also plays a major role in establishing correct cue strength. The RT data showed that advanced learners who have had more input across a longer period of time showed performance closer to that of native speakers. This study examined only the most basic aspects of honorific agreement marking. The nuances of the larger system can challenge even young native speakers in high school. Given the social details involved in mastering this system, we can estimate that it will take several years before L2 learners can fully master this system. It is possible that additional data from Japanese children and L2 learners could end up significantly complicating the relatively direct account of the processing of honorific agreement we have presented here.

\section{ACKNOWLEDGMENTS}

This research was partially supported by a fellowship from the Japan Society for the Promotion of Science (to Y.Y.). Thanks to Paul Hopper and anonymous reviewers for 
Yoshimura \& MacWhinney: Honorifics in Japanese

comments on earlier versions of the manuscript. Parts of this work were presented at the 2003 Second Language Research Forum.

\section{REFERENCES}

Brown, P., \& Levinson, S. (1978). Universals in language usage: Politeness phenomena. In E. Goody (Ed.), Questions and politeness. Cambridge: Cambridge University Press.

Brown, R., \& Gilman, A. (1960). The pronouns of power and solidarity. In T. A. Sebeok (Ed.), Style in language. Cambridge, MA: MIT Press.

Clark, H. (1996). Using language. Cambridge: Cambridge University Press.

Devescovi, A., D’Amico, S., Smith, S., Mimica, I., \& Bates, E. (1998). The development of sentence comprehension in Italian and Serbo-Croatian: Local versus distributed cues. In D. Hillert (Ed.), Syntax and semantics: Vol. 31. Sentence processing: A cross-linguistic perspective (pp. 345-377). San Diego, CA: Academic Press.

Gass, S. (1987). The resolution of conflicts among competing systems: A bidirectional perspective. Applied Psycholinguistics, 8, 329-350.

Halliday, M. (1966). Notes on transitivity and theme in English: Part 1. Journal of Linguistics, 2, $37-71$.

Kail, M. (1989). Cue validity, cue cost, and processing types in French sentence comprehension. In B. MacWhinney \& E. Bates (Eds.), The crosslinguistic study of language processing (pp. 77-117). New York: Cambridge University Press.

Kamio, A. (1994). The theory of territory of information: The case of Japanese. Journal of Pragmatics, $21,67-100$.

Kamio, A. (1995). Territory of information in English and Japanese and psychological utterances. Journal of Pragmatics, 24, 235-264.

Kanaya, T. (2002). Nihongo ni shugo wa iranai [Japanese does not need a subject]. Tokyo: Kodansha.

Kempe, V., \& MacWhinney, B. (1998). The acquisition of case-marking by adult learners of Russian and German. Studies in Second Language Acquisition, 20, 543-587.

Kempe, V., \& MacWhinney, B. (1999). Processing of morphological and semantic cues in Russian and German. Language and Cognitive Processes, 14, 129-171.

Kilborn, K., \& Ito, T. (1989). Sentence processing in Japanese-English and Dutch-English bilinguals. In B. MacWhinney \& E. Bates (Eds.), The crosslinguistic study of sentence processing (pp. 257-291). New York: Cambridge University Press.

Kuno, S. (1973). The structure of the Japanese language. Cambridge, MA: MIT Press.

Li, P., Bates, E., \& MacWhinney, B. (1993). Processing a language without inflections: A reaction time study of sentence interpretation in Chinese. Journal of Memory and Language, 32, 169-192.

MacWhinney, B. (2008a). A unified model. In P. Robinson \& N. Ellis (Eds.), Handbook of cognitive linguistics and second language acquisition. Mahwah, $\mathrm{NJ}$ : Erlbaum.

MacWhinney, B. (2008b). How mental models encode embodied linguistic perspectives. In R. Klatzky, B. MacWhinney, \& M. Behrmann (Eds.), Embodiment, ego-space, and action (pp. 369-410). Mahwah, NJ: Erlbaum.

MacWhinney, B., \& Bates, E. (Eds.). (1989). The crosslinguistic study of sentence processing. New York: Cambridge University Press.

MacWhinney, B., Bates, E., \& Kliegl, R. (1984). Cue validity and sentence interpretation in English, German, and Italian. Journal of Verbal Learning and Verbal Behavior, 23, 127-150.

MacWhinney, B., Pléh, C., \& Bates, E. (1985). The development of sentence interpretation in Hungarian. Cognitive Psychology, 17, 178-209.

Matessa, M., \& Anderson, J. (2000). Modeling focused learning in role assignment. Language and Cognitive Processes, 15, 263-292.

McDonald, J. L., \& Heilenman, K. (1991). Determinants of cue strength in adult first and second language speakers of French. Applied Psycholinguistics, 12, 313-348.

McDonald, J. L., \& MacWhinney, B. (1989). Maximum likelihood models for sentence processing research. In B. MacWhinney \& E. Bates (Eds.), The crosslinguistic study of sentence processing (pp. 397-421). New York: Cambridge University Press.

McDonald, J. L., \& MacWhinney, B. (1991). Levels of learning: A microdevelopmental study of concept formation. Journal of Memory and Language, 30, 407-430. 
Yoshimura \& MacWhinney: Honorifics in Japanese

Mikami, A. (1960). Zou wa hana ga nagai [Elephants have long noses]. Tokyo: Kuroshio.

Pearlmutter, N., Garnsey, S. M., \& Bock, K. (1999). Agreement processes in sentence comprehension. Journal of Memory and Language, 41, 427-456.

Pléh, C. (1989). The development of sentence interpretation in Hungarian. In B. MacWhinney \& E. Bates (Eds.), The crosslinguistic study of sentence processing (pp. 158-184). New York: Cambridge University Press.

Sasaki, Y., \& MacWhinney, B. (2005). Language acquisition research based on the competition model. In Y. Shirai (Ed.), Handbook of Japanese psycholinguistics (pp. 318-328). Cambridge: Cambridge University Press.

Shibatani, M. (1985). Shugo prototaipu ron [Subject prototype theory]. Nihongo Gaku, 4, 4-16.

Shibatani, M. (1990). The languages of Japan. Cambridge: Cambridge University Press.

Slobin, D. (1985). Crosslinguistic evidence for the language-making capacity. In D. Slobin (Ed.), The crosslinguistic study of language acquisition: Vol. 2. Theoretical issues (pp. 1157-1256). Hillsdale, NJ: Erlbaum.

$\mathrm{Su}$, I. (2001). Transfer of sentence processing strategies: A comparison of L2 learners of Chinese and English. Applied Psycholinguistics, 22, 83-112.

Weyerts, H., Penke, M., Münte, T., Heinze, H.-J., \& Clahsen, H. (2002). Word order in sentence processing: An experimental study of verb placement in German. Journal of Psycholinguistic Research, 31, 211-268.

Whorf, B. (1967). Language, thought, and reality. Cambridge, MA: MIT Press. 